\title{
Evaluation of surgical treatment
} for incidental gallbladder carcinoma diagnosed during or after laparoscopic cholecystectomy: single center results

\author{
Masashi Utsumi*, Hideki Aoki, Tomoyoshi Kunitomo, Yutaka Mushiake, Isao Yasuhara, Takashi Arata, \\ Koh Katsuda, Kohji Tanakaya and Hitoshi Takeuchi
}

\begin{abstract}
Background: Laparoscopic cholecystectomy (LC) is the accepted standard management for benign gallbladder disease. $L C$ rarely results in a diagnosis of incidental gallbladder carcinoma (IGBC). The aim of our study was to report our experience with IGBC diagnosed during or following LC.

Methods: Between January 2008 and January 2015, 352 patients underwent LC at Iwakuni Clinical Center. Among these patients, 8 (2.3\%) were diagnosed with IGBC. We evaluated their characteristics, surgical related variables, histopathological findings and surgical outcomes.

Results: Patient median age was 71 (range 49-88) years, and 3 out of 8 were female. All patients with IGBC were Japanese. The grade of cancer was as follows: pT1a (3 cases), pT2 (4 cases) and pT3 (1 case). Two patients with pT2 disease underwent radical surgery. The median follow-up time of these patients was 24 (range 11-80) months. All patients are still alive and two of three patients who refused radical surgery have developed recurrence (liver metastases and recurrence in the peritoneum).
\end{abstract}

Conclusions: Although the number of cases was small, the results of this study further support the suggestion that gallbladder carcinoma may be curable if diagnosed as IGBC at an early stage. If the cancer has reached an advanced stage, radical surgery should be performed.

Keywords: Incidental gallbladder carcinoma, Laparoscopic cholecystectomy, Surgical treatment

\section{Background}

Gallbladder cancer (GBC) is a relatively rare neoplasm and is considered to be an aggressive and highly lethal disease. It is the most frequently occurring malignancy of the biliary tract and the fifth most common gastrointestinal cancer [1]. Only $30 \%$ of gallbladder carcinomas are suspected preoperatively, and the remaining $70 \%$ are usually discovered incidentally by pathological examination during or after surgery [2].

*Correspondence: masashi11232001@yahoo.co.jp

Department of Surgery, National Hospital Organization, Iwakuni Clinical

Center, 1-1-1 Atago-machi, Iwakuni, Yamaguchi 740-8510, Japan
In recent years, laparoscopic cholecystectomy (LC) has become the accepted gold standard management for gallbladder disease. With the advantages of a shorter hospital stay, decreased post-operative pain and earlier resumption of normal activities compared to open cholecystectomy, this procedure has now become routine in the treatment of benign gallbladder disease worldwide. LC that is performed for benign gallbladder disease rarely results in a diagnosis of unexpected gallbladder carcinoma. Incidental gallbladder carcinoma (IGBC) is defined as carcinoma of the gallbladder suspected for the first time during cholecystectomy, or accidentally found on histological examination of gallbladder. The estimated incidence of IGBC diagnosed by cholecystectomy is 
$1-2 \%$ [3]. Although patients with GBC have a poor prognosis, most IGBC tumors tend to be at an early stage of development. Hence, radical second surgery is performed in most patients with IGBC, and improved prognosis is usually reported [4-7]. However management of IGBC is a difficult issue in the absence of established guidelines. The primary aim of our study was to evaluate the incidence, clinicopathological characteristics and outcome of patients with IGBC.

\section{Methods}

The study was approved by Ethics Committee at Iwakuni Clinical Center. Between January 2008 and January 2015, 352 patients underwent $\mathrm{LC}$ at Iwakuni Clinical Center. Among these patients, $8(2.3 \%)$ were diagnosed with IGBC. Their clinical presentation, ultrasonography findings, preoperative diagnosis, intraoperative findings, histopathological records and surgical outcomes were reviewed. We excluded from the study all patients with suspected pre-operative malignancy. All LCs were executed using the standard 4 trocar technique, and EndBag protected gallbladder (GB) extraction. Patients were staged according to the American Joint Committee on Cancer 7th edition tumor node metastasis clinical staging system for GBC [8]. We have advocated additional radical surgery for patients with pT2 or pT3 tumors $[4,5]$. Regarding the surgical radicalization procedure, we performed hepatic S4a + S5 resection with hepatic peduncle lymphadenectomy $[4,5,9]$. The completeness of the resection was classified as follows: $\mathrm{R} 0$, no residuals in the hepatic margins; R1, a microscopically positive margin; and R2 macroscopic residuals in the hepatic margin.

\section{Results}

The clinical characteristics of patients with IGBC during or following LC are detailed in Table 1. Of the eight patients three were female, and the median age of all patients was 71 (range, 49-88) years. All patients with IGBC were Japanese. Five patients presented with complaints of pain in the right hypochondrium. Ultrasonography revealed a thickened gallbladder in four patients and multiple polyps in two. Gall stones were observed in five patients. No patient exhibited pancreaticobiliary malfunction on magnetic resonance cholangiopancreatography. The preoperative diagnosis of the eight patients with incidental IGBC was as follows: cholecystitis (2 cases), gallbladder polyps (2 cases), gallbladder stones (4 cases) and adenomyomatosis ( 2 cases). There was some overlapping.

The histopathological characteristics and surgical outcomes of IGBC patients during or following LC are detailed in Table 2. Intraoperatively, in one patient, there was a tumor suspected of being an adenocarcinoma, and frozen sectioning was performed; a diagnosis of adenocarcinoma was confirmed. The GBC was found to have invaded the transverse colon. Consequently, we abandoned open cholecystectomy with removal of cystic duct lymph node and performed colectomy. Also, in case with swelling cystic duct node, we removed it. The remaining seven patients were diagnosed postoperatively on the basis of the histopathological examination.

According to the pathological TNM classification system, the tumor stages were as follows: pT1a ( 3 cases); pT2 (4 cases); and pT3 (1 case). The pathological characteristics of the tumors were as follows: well differentiated adenocarcinoma (6 cases); moderately differentiated adenocarcinoma ( 1 case); and poorly differentiated adenocarcinoma (1 case).

Three patients with pT1a disease had no additional surgery, and there was no recurrence. Two patients with pT2 disease underwent radical surgery and there was no recurrence. The remaining three patients with pT2 disease ( 2 cases) or pT3 disease ( 1 case) refused radical surgery. All patient had no adjuvant therapy (chemotherapy

Table 1 Clinical characteristics of patients with incidental gallbladder carcinoma during or following laparoscopic cholecystectomy

\begin{tabular}{|c|c|c|c|c|}
\hline $\begin{array}{l}\text { Patient } \\
\text { number }\end{array}$ & Clinical presentation & $\begin{array}{l}\text { Pre-ALP } \\
\text { (units/L) }\end{array}$ & Ultrasonographic finding & Preoperative diagnosis \\
\hline 1 & None & 214 & Multiple GB polyps & GB polyp \\
\hline 2 & Right hypochondralgia & 315 & Multiple GB stones & GB stone \\
\hline 3 & None & 178 & Multiple GB polyps & GB polyp \\
\hline 4 & Right hypochondralgia & 365 & Multiple GB stones & GB stone, cholecystitis \\
\hline 5 & Right hypochondralgia & 272 & GB wall thickening, GB stones & GB stone, cholecystitis \\
\hline 6 & None & 189 & Segmental GB wall thickening & Adenomyomatosis \\
\hline 7 & Right hypochondralgia & 132 & Segmental GB wall thickening, multiple GB stones & Adenomyomatosis \\
\hline 8 & Right hypochondralgia & 313 & Segmental GB wall thickening, multiple GB stones & GB stone \\
\hline
\end{tabular}

GB gallblader, Pre-ALP preoperative serum level of alkaline phosphatase 


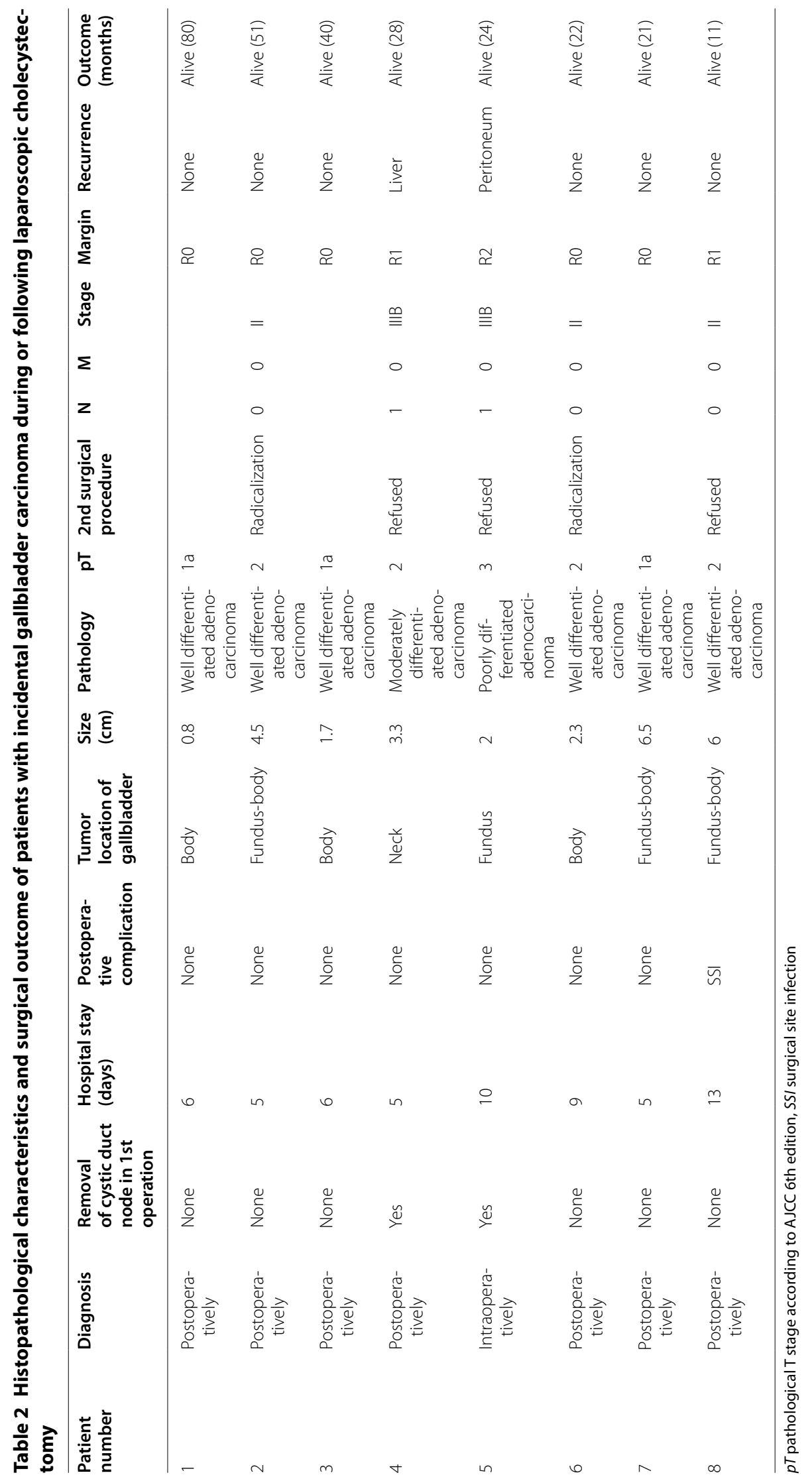


or chemoradiation). Follow up of both patients undergoing radical surgery and refusing radical surgery is blood examination including tumor marker every 2 months and CT imaging studies every 4 months. The median followup time was 24 (range 11-80) months. All patients are still alive and two of the three patients who refused radical surgery developed recurrence (liver metastases and recurrence in the peritoneum, respectively). The remaining patients were disease-free during follow-up. We did not find any patients with port-site recurrence during the follow-up period. Patients with pT2/T3 received no adjuvant chemotherapy or chemoradiation post-operatively.

\section{Discussion}

The incidence of IGBC during or after LC has been reported to be $0.19-3.3 \%[5,10-12]$. Because of the increased use of LC and difficulty regarding the preoperative diagnosis of GBC, IGBC has become more frequent $[11,13]$. In the present study, the rate of occurrence of IGBC was $2.3 \%$.

Some studies have reported that risk factors for IGBC are as follows: sex (female); obesity; age $>65$ years; cholelithiasis; polypoid lesions; Asian or African American; and an elevated alkaline phosphatase level [14-17]. In our study, three patients were female and their median age was 64 years. All of our patients with IGBC were Asian. The symptoms related to IGBC can be relatively nonspecific, with the early symptoms mimicking those of GB stones or cholecystitis. GB stones are found in $70-98 \%$ of patients with GBC. Cholelithiasis causes chronic irritation and inflammation of the GB, which leads to the development of mucosal dysplasia and subsequent carcinoma; it takes a long time for the promotion of tumor proliferation and the occurrence of malignancy [18]. In our study, pain in the right hypochondrium was present in four patients. An additional three patient had no symptoms. None of our patients presented with a clinical profile that differed from that of typical patients with GB stones or cholecystitis. In the early stages, it is difficult to differentiate between GBC and cholecystitis, because thickening of the GB wall is a feature of both diseases [19].

Frozen sectioning should be performed when surgeons suspect malignancy in intraoperative finding $[20,21]$. In our study, the intraoperative assessment of the GB using frozen sections revealed GBC in one patient with GB wall thickening and cholecystitis. Consequently, we switched from LC to open cholecystectomy. The efficacy of frozen sections was poor with respect to the diagnosis of carcinoma in situ [20,21]. Kwon et al. also found that diagnosis using frozen sections did not reliably detect the carcinoma in situ and the depth of invasion of GBC; thus, it should not be considered a definitive diagnostic procedure [22]. The most appropriate approach for diagnosis at present is to macroscopically examine the $G B$ mucosa during surgery, and to perform frozen sectioning for any suspected lesion.

The survival rate of IGBC patients is high with a median survival rate of $21.2-60$ months $[5,10,11]$. All patients in our studies were alive at a mean follow-up time of 24 months. One reason for this may be early diagnosis, as in the present study in which most of the cases involved stage 1 or 2 tumors, thereby resulting in better prognoses. However, we could not find any common characteristic that could differentiate these GB carcinomas from benign tumors in laboratory and sonographic findings. The difficulty in early diagnosis of GBC results from its poor specificity and ambiguity regarding clinical symptoms [23-25]. Tumor differentiation is an independent prognostic factor that affects survival [5]. In the present study, six of eight tumors were well differentiated adenocarcinomas.

Surgical resection is the only curative therapy for GBC $[15,26,27]$. Determining the therapeutic approach for GBC in accordance with disease stage is supported by most authors [27, 28]. There is a consensus that simple cholecystectomy or LC is an adequate treatment for pT1a. pT2 and higher stages should be treated using additional radical surgery using hepatic $\mathrm{S} 4 \mathrm{a}+\mathrm{S} 5$ resection with hepatic peduncle lymphadenectomy $[9,15,29$, 30]. For patients with $\mathrm{T} 1 \mathrm{~b}$ disease, the correct approach is still debated and some authors recommend hepatic gallbladder bed resection with hepatic peduncle lymphadenectomy [31, 32]. In the present study, the survival of patients with pT1 disease was favorable after LC. Two patients with pT2 disease underwent additional radical surgery and had good outcomes. Other patients with pT2 and pT3 disease refused additional radical surgery and later developed recurrence.

Laparoscopic cholecystectomy appears to have resulted in the earlier discovery of GBC in some patients, resulting in an increased probability of successful treatment [33]. Precise surgery is essential in obtaining a good outcome from IGBC treatment [4]. The present study was retrospective and involved a small number of patients. A study involving a considerably larger sample size will be required to evaluate the surgical outcome and effectiveness of radical surgery for IGBC.

\section{Conclusions}

The incidence of IGBC detected during laparoscopic cholecystectomy in this single center study was found to be $2.3 \%$. No association could be found with risk factors that have been reported by other authors. Although the number of patients enrolled was small, our findings further support the suggestion that GB carcinoma may be 
curable if diagnosed at an early stage as IGBC. pT1b or greater tumor stages identified on LC may benefit from additional radical resection.

\section{Abbreviations}

GB: gallbladder; GBC: gallbladder cancer; IGBC: incidental gallbladder carcinoma; LC: laparoscopic cholecystectomy.

\section{Authors' contributions}

$M U, H A, M U, T K, Y M, N K, I Y, K K, K T$ and $H T$ designed the study. HA, MU and TK treated and observed the patients. MU prepared the manuscript and performed the literature search. HA corrected and revised the manuscript. All authors read and approved the final manuscript.

\section{Acknowledgements}

The authors wish to thank Rie Yamasaki for the pathological diagnosis.

\section{Competing interests}

The authors declare that they have no competing interests.

\section{Availability of data and materials}

The datasets during and/or analysed during the current study available from the corresponding author on reasonable request.

\section{Consent of publication}

Written informed consent was obtained from the patients for the use of clinical data.

\section{Ethics approval and consent to participate}

The study was approved by the Ethics Committee at Iwakuni Clinical Center. Written informed consent was provided by all participants.

Received: 29 December 2015 Accepted: 13 January 2017

Published online: 21 January 2017

\section{References}

1. Siegel R, Desantis C, Jemal A. Colorectal cancer statistics, 2014. CA Cancer J Clin. 2014:64(2):104-17.

2. Goetze T, Paolucci V. Does laparoscopy worsen the prognosis for incidental gallbladder cancer? Surg Endosc. 2006;20(2):286-93.

3. Isambert M, Leux C, Metairie S, Paineau J. Incidentally-discovered gallbladder cancer: when, why and which reoperation? J Visc Surg. 2011;148(2):e77-84.

4. Tian YH, Ji X, Liu B, Yang GY, Meng XF, Xia HT, Wang J, Huang ZQ, Dong $\mathrm{JH}$. Surgical treatment of incidental gallbladder cancer discovered during or following laparoscopic cholecystectomy. World J Surg. 2015;39(3):746-52.

5. Choi SB, Han HJ, Kim CY, Kim WB, Song TJ, Suh SO, Kim YC, Choi SY. Incidental gallbladder cancer diagnosed following laparoscopic cholecystectomy. World J Surg. 2009;33(12):2657-63.

6. Singh S, Agarwal AK. Gallbladder cancer: the role of laparoscopy and radical resection. Ann Surg. 2009;250(3):494-5.

7. Ferrarese AG, Solej M, Enrico S, Falcone A, Catalano S, Pozzi G, Marola S, Martino V. Diagnosis of incidental gallbladder cancer after laparoscopic cholecystectomy: our experience. BMC Surg. 2013;13(Suppl 2):S20.

8. Edge SB, Compton CC. The American Joint Committee on Cancer: the 7th edition of the AJCC cancer staging manual and the future of TNM. Ann Surg Oncol. 2010;17(6):1471-4.

9. Choi SB, Han HJ, Kim CY, Kim WB, Song TJ, Suh SO, Kim YC, Choi SY. Surgical outcomes and prognostic factors for T2 gallbladder cancer following surgical resection. J Gastrointest Surg. 2010;14(4):668-78.

10. Zhang WJ, Xu GF, Zou XP, Wang WB, Yu JC, Wu GZ, Lu CL. Incidental gallbladder carcinoma diagnosed during or after laparoscopic cholecystectomy. World J Surg. 2009;33(12):2651-6.
11. Tantia O, Jain M, Khanna S, Sen B. Incidental carcinoma gall bladder during laparoscopic cholecystectomy for symptomatic gall stone disease. Surg Endosc. 2009;23(9):2041-6.

12. Shrestha R, Tiwari M, Ranabhat SK, Aryal G, Rauniyar SK, Shrestha HG. Incidental gallbladder carcinoma: value of routine histological examination of cholecystectomy specimens. Nepal Med Coll J. 2010;12(2):90-4.

13. Zurrida S, Veronesi U. A new TNM classification for breast cancer to meet the demands of the present and the challenges of the future. Women's Health. 2011;7(1):41-9.

14. Bertran E, Heise K, Andia ME, Ferreccio C. Gallbladder cancer: incidence and survival in a high-risk area of Chile. Int J Cancer. 2010;127(10):2446-54.

15. Chan SY, Poon RT, Lo CM, Ng KK, Fan ST. Management of carcinoma of the gallbladder: a single-institution experience in 16 years. J Surg Oncol. 2008;97(2):156-64.

16. Pitt SC, Jin LX, Hall BL, Strasberg SM, Pitt HA. Incidental gallbladder cancer at cholecystectomy: when should the surgeon be suspicious? Ann Surg. 2014:260(1):128-33.

17. Solaini L, Sharma A, Watt J, losifidou S, Chin Aleong JA, Kocher HM. Predictive factors for incidental gallbladder dysplasia and carcinoma. J Surg Res. 2014;189(1):17-21.

18. SuJata J, Rana S, Sabina K, Hassan MJ, JaiRaJpuRi ZS. Incidental gall bladder carcinoma in laparoscopic cholecystectomy: a report of 6 cases and a review of the literature. J Clin Diagnostic Res. 2013;7(1):85.

19. Bach AM, Loring LA, Hann LE, Illescas FF, Fong Y, Blumgart LH. Gallbladder cancer: can ultrasonography evaluate extent of disease? J Ultrasound Med. 1998;17(5):303-9.

20. Frauenschuh D, Greim R, Kraas E. How to proceed in patients with carcinoma detected after laparoscopic cholecystectomy. Langenbeck's Arch Surg/Deutsche Gesellschaft fur Chirurgie. 2000;385(8):495-500.

21. Aoki T, Tsuchida A, Kasuya K, Inoue K, Saito H, Koyanagi Y. Is frozen section effective for diagnosis of unsuspected gallbladder cancer during laparoscopic cholecystectomy? Surg Endosc. 2002;16(1):197-200.

22. Kwon AH, Imamura A, Kitade H, Kamiyama Y. Unsuspected gallbladder cancer diagnosed during or after laparoscopic cholecystectomy. J Surg Oncol. 2008;97(3):241-5.

23. Misra S, Chaturvedi A, Misra NC, Sharma ID. Carcinoma of the gallbladder. Lancet Oncol. 2003;4(3):167-76.

24. Shi JS, Wang JS, Liu G, Yu YL, Lu Y, Jiao XY, Yang YJ, Li GC, Han Y. Early diagnosis of primary gallbladder carcinoma. Hepatobiliary Pancreat Dis Int. 2002;1 (2):273-5

25. Misra MC, Guleria S. Management of cancer gallbladder found as a surprise on a resected gallbladder specimen. J Surg Oncol. 2006;93(8):690-8.

26. Kai M, Chijiiiwa K, Ohuchida J, Nagano M, Hiyoshi M, Kondo K. A curative resection improves the postoperative survival rate even in patients with advanced gallbladder carcinoma. J Gastrointest Surg. 2007;1 1(8):1025-32.

27. Ong SL, Garcea G, Thomasset SC, Neal CP, Lloyd DM, Berry DP, Dennison AR. Ten-year experience in the management of gallbladder cancer from a single hepatobiliary and pancreatic centre with review of the literature. HPB. 2008;10(6):446-58.

28. Todoroki T, Kawamoto T, Takahashi H, Takada Y, Koike N, Otsuka M, Fukao K. Treatment of gallbladder cancer by radical resection. Br I Surg. 1999;86(5):622-7.

29. Chijiiwa K, Noshiro H, Nakano K, Okido M, Sugitani A, Yamaguchi K, Tanaka M. Role of surgery for gallbladder carcinoma with special reference to lymph node metastasis and stage using western and Japanese classification systems. World J Surg. 2000;24(10):1271-7.

30. Konstantinidis IT, Deshpande V, Genevay M, Berger D, Fernandez-del Castillo C, Tanabe KK, Zheng H, Lauwers GY, Ferrone CR. Trends in presentation and survival for gallbladder cancer during a period of more than 4 decades: a single-institution experience. Arch Surg. 2009;144(5):441-7.

31. Shukla PJ, Barreto G, Kakade A, Shrikhande SV. Revision surgery for incidental gallbladder cancer: factors influencing operability and further evidence for T1b tumours. HPB. 2008;10(1):43-7.

32. Yildirim E, Celen O, Gulben K, Berberoglu U. The surgical management of incidental gallbladder carcinoma. Eur J Surg Oncol. 2005;31(1):45-52.

33. Shih SP, Schulick RD, Cameron JL, Lillemoe KD, Pitt HA, Choti MA, Campbell KA, Yeo CJ, Talamini MA. Gallbladder cancer: the role of laparoscopy and radical resection. Ann Surg. 2007;245(6):893-901. 